Eur. J. Clin. Chem. Clin. Biochem.

Vol. 32, 1994, pp. 285-291

(c) 1994 Walter de Gruyter \& Co. Berlin · New York

\title{
Development of Enzyme Immunoassays Specific for Keratan Sulphate- and Core-Protein-Epitopes of the Large Aggregating Proteoglycan from Human Articular Cartilage ${ }^{1}$ )
}

\author{
By Dagmar-Christiane Fischer ', Susanne Kolbe-Busch ', G. Stöcker ${ }^{1}$, A. Hoffmann ${ }^{2}$ and H.-D. Haubeck ${ }^{1}$ \\ 1 Institut fiir Klinische Chemie und Pathobiochemie der RWTH Aachen, Aachen, Germany \\ 2 Abteilung für Rheumatologie, Medizinische Hochschule Hannover, Hannover, Germany
}

(Received June 24/August 25, 1993)

Dedicated to Prof. Dr. Dr: Helmut Greiling on the occasion of his 65th birthday

Summary: In the course of chronic inflammatory and degenerative joint diseases proteoglycans are degraded by the action of proteases and oxygen radicals. Therefore, proteoglycan fragments, released from cartilage into the peripheral blood, might be useful markers of cartilage degradation. Sensitive enzyme immunoassays are useful for the detection of these proteoglycan fragments in serum. We therefore developed specific monoclonal antibodies against the large aggregating proteoglycan (aggrecan), which has been isolated and purified from human articular cartilage. Two monoclonal antibodies which recognize a novel cartilage-specific epitope on the keratan sulphate chain of aggrecan (mAb 4B3/D10) and an epitope of the core-protein of aggrecan (4G4/A10) were selected for the development of competitive enzyme-immunoassays. These assays allow the sensitive and specific detection of cartilage-derived proteoglycan fragments, not only in synovial fluid but also in serum. They can now be used for the study of inflammatory and degenerative joint diseases.

\section{Introduction}

In the course of chronic inflammatory and degenerative joint diseases, proteoglycans are degraded by the action of proteases which are released either by inflammatory cells, e.g. granulocytes and monocytes, or by chondrocytes themselves. Therefore, proteoglycan fragments released from the cartilage may be useful markers of cartilage degradation. During the past few years several groups have tried to use monoclonal antibodies specific for keratan sulphate chains of the large aggregating proteoglycan (aggrecan), a major component of the extracellular matrix of cartilage, for the determination of keratan sulphate levels in serum and synovial fluid of

\footnotetext{
') This work was supported by grant No. 01VM8915/6 from the Bundesministerium fur Forschung und Technologie, Bonn.
}

patients with different joint diseases (1-7). However, the use of these monoclonal antibodies, which recognize an epitope in the disulphated region of the keratan sulphate chain (8), has provided no clear correlation between keratan sulphate levels and the degree of cartilage degradation or disease activity (1-7). A major reason might be that these antibodies are not specific for aggrecan from articular cartilage, but also react with keratan sulphate from other sources, e.g. intervertebral disc, cornea or blood vessels $(9-11)$. These data clearly demonstrate that monitoring of cartilage damage will require monoclonal antibodies with much higher specificity for cartilage than those used previously. Therefore we decided to generate novel monoclonal antibodies against different cartilage-specific epitopes of the large aggregating proteoglycan. These antibodies have now been used for the development of sensitive antigen-inhibition 
enzyme-immunoassays specific for keratan sulphateand core-protein-epitopes of the large aggregating protcoglycan.

\section{Materials and Methods}

\section{Reagents}

Scphadex G-25, Sepharose Q, Protein-G-Sepharose, the TSK G $4000 \mathrm{SW}$ column $(7.5 \mathrm{~mm} \times 300 \mathrm{~mm})$, the TSK G SWP guardcolumn $(7.5 \mathrm{~mm} \times 75 \mathrm{~mm})$ and preformed gels for SDS-polyacrylamide-gel elcctrophoresis (4-15\% gradient) were obtained from Pharmacia/LKB (Frciburg, Germany). Hydroxyapatite and ZctaProbe blotting membrane were obtained from Bio-Rad (Munich, Germany). Polyvinylidenefluoride blotting membranes (Fluorotrans) werc purchased from Pall (Dreieich, Germany). High molecular mass standards, 3-[3-cholamido-propyl)-dimethylamino]-1propane-sulphonate (CHAPS), benzamidine hydrochloride, 6-aminohexanoic acid, phenylmethylsulphonyl fluoride and N-ethylmalcinimide were purchased from Sigma (Deisenhofen, Germany). Diaminobenzamidine-tetrahydrochloride was from Serva (Heidclberg, Germany), o-phenylenediamine (OPD, $2 \mathrm{mg}$ tablets) and rabbil-anti-mouse-Ig-antiscrum were from DAKO (Kopenhagen, Denmark). Peroxidase-conjugated streptavidin and peroxidase-conjugated goat-antibodies against mouse-IgG were from Dianova (Hamburg, Gcrmany). Chondroitin sulphate lyase AC (EC 4.2.2.5 $)^{2}$, chondroitin sulphate lyase $A B C$ (EC 4.2.2.4), keratan sulphate hydrolyase (EC 3.2.1.103), keratan sulphate endo- $\beta-\mathrm{N}$ acetyl-glucosaminidase (keratanase II) and the keratan sulphatespecific monoclonal antibody $\mathrm{mAB}$ 5D4 were obtained from Seikagaku (Tokio, Japan). Sulphosuccinimidyl-6-(biotinamido)-hexanoate (NHS-LC-biotin) was from Pierce (Munich, Germany). Polycthylene glycol 1500 (PEG 1500) and trypsin (EC 3.4.21.4) was from Boehringer Mannheim (Mannheim, Germany). All other reagents were of analytical grade (Merck, Darmstadt, Germany).

\section{Mcthods}

Isolation and purification of the large aggregating proteoglycan from human articular cartilage

Isolation and purification of the large aggrcgating proteoglycan (aggrecan) from human articular cartilage was carried out as described $(12-15)$ and is schematically shown in figure 1. Cartilage from the femur condyles of 14 donors was pooled; the age of the donors was in the range of 10 to 82 years. Briefly, proteoglycans were extracted from cartilage by $4 \mathrm{~mol} / \mathrm{l}$ guanidine hydrochloride, $0.05 \mathrm{~mol} / \mathrm{l}$ sodium acetate, ( $\mathrm{pH} 5.8$ ) containing $5 \mathrm{~g} / \mathrm{l}$ CHAPS and the protease inhibitors benzamidine hydrochloride $(0.005 \mathrm{~mol} / \mathrm{l})$, 6-aminohexanoic acid $(0.1 \mathrm{~mol} / \mathrm{l})$, phenylmethylsulphonyl fluoride $(0.005 \mathrm{~mol} / \mathrm{l}), \mathrm{N}$-ethylmaleimide $(0.01 \mathrm{~mol} / \mathrm{l})$, and EDTA $(0.05$ $\mathrm{mol} / \mathrm{l})$. The $4 \mathrm{~mol} / \mathrm{l}$ guanidine hydrochloride extract of cartilage was equilibrated with $0.05 \mathrm{~mol} / 1$ Tris, $0.05 \mathrm{~mol} / \mathrm{l}$ sodium acetate buffer (pH 5.8) containing $7 \mathrm{~mol} / 1$ urea, $0.05 \mathrm{~mol} / \mathrm{l} \mathrm{NaCl}, 0.05$ $\mathrm{mol} / \mathrm{l} \mathrm{LiCl}, 2 \mathrm{~g} / \mathrm{l}$ CHAPS and proteasc-inhibitors $(0.001 \mathrm{~mol} / \mathrm{l} \mathrm{N}$ cthylmaleimide, $0.002 \mathrm{~mol} / \mathrm{l}$ benzamidine hydrochloride and 0.001 $\mathrm{mol} / \mathrm{l}$ phenylmethylsulphonyl fluoride) by size-exclusion chromatography on Sephadex G-25. Aggrecan was isolated by anion-exchange chromatography on Scpharosc Q (Pharmacia/LKB, Freiburg, Germany) and further purified by hydroxyapatite chromatography.

\section{2) Enzymes}

Chondroitinasc AC (chondroitin sulphatc lyase AC, EC 4.2.2.5)

Chondroitinase $A B C$ (chondroitin sulphate lyase $A B C, E C$ 4.2.2.4)

Kcratanase (keratan sulphate hydrolyase, EC 3.2.1.103)

Keratanase II (keratan sulphate endo- $\beta-\mathrm{N}$-acetylglucosaminidase)

Trypsin (EC 3.4.21.4)
Characlerizution of the large aggregating proteoglycan from human articular cartilage

For amino acid and amino sugar analysis, an aggrecan sample was treated with $3 \mathrm{~mol} / \mathrm{HCl}$ at $105^{\circ} \mathrm{C}$ for $15 \mathrm{~h}$. Analysis was performed on a LKB-Alphaplus amino acid analyser (Pharmacia/LKB, Freiburg, Germany).

The prepared aggrecan was showri to be homogeneous by sizeexclusion chromatography on TSK 4000 , and was identified by SDS-PAGE and western blot analysis of a native and enzymatically digested biotinylated sample (16).

\section{Enzymatic and chemical deglycosylation}

Enzymatic digestion with chondroitin sulphate lyase AC (EC 4.2.2.5), chondroitin sulphate lyase $A B C$ (EC 4.2.2.4), keratan sulphate hydrolyase (EC 3.2.1.103) and keratanase II was performed in the presence of proteinase inhibitors as described by Oike et al. (17). For chemical deglycosylation a lyophilizied aggrecan sample was treated with trifluormethanesulphonic acid in anisole $(18,19)$.

\section{Monoclonal antibodies}

Monoclonal antibodies were raised in mice according to a modified protocol of the basic outline of Köhler \& Milstein (20). Briefly: $100 \mu \mathrm{g}$ of aggrecan in a volume of $300 \mu \mathrm{l}$ were mixed with an equal volume of Freund's complete adjuvant and injected intraperitoneally and subcutaneously into 8 week-old BALB/c female mice. The mice received booster injections after 6 weeks in Freund's incomplete adjuvant and a final injection 3 days before the fusion. Serum titres of preimmune and immune sera were determined by the use of a slot blot enzyme-immuno assay (see below). Spleen cells of the mouse with the highest serum titre were fused with the $\mathrm{BALB} / \mathrm{c}$ myeloma X63-Ag8/653, using polyethylene glycol. Cells were plated in 96-well plates in Dulbecco's minimal essential medium containing foetal calf serum (volume fraction 0.1 ) and hypoxanthine-aminopterine-thymidine. Hybridoma supernatants were tested by ELISA (see below). Hybridomas that showed a positive reaction were cloned and subcloned by limiting dilution.

\section{Screening and characterization of monoclonal antibodies}

Supernatants were tested for specific antibody against aggrecan by the use of a slot blot enzymc immuno assay on a zeta probe membrane (Bio-Rad, Munich, Germany). Briefly: $50 \mathrm{ng}$ of the aggrecan preparation were incubated per slot for $10 \mathrm{~min}$ at room temperature on a zeta probe membrane. After blocking of the membrane with blotto $(20 \mathrm{~g} / \mathrm{l}$ dry milk powder in phosphate buffered saline) for $2 \mathrm{~h}, 200 \mu \mathrm{l}$ of hybridoma supernatants were incubated for $4 \mathrm{~h}$ at room temperature. Bound antibodies were detected by a peroxidase-conjugated second antibody from goat, using diaminobenzidine $/ \mathrm{H}_{2} \mathrm{O}_{2}$ as substrate. Subclass determination of the specific monoclonal antibodies was done by an ELISA, using subclass specific antisera (Dianova, Hamburg, Germany). Monoclonal antibodies from cell culture supernatants were purified by protein $G$ affinity chromatography according to the manufacturer's instruotions (Pharmacia Fine Chemicals, Uppsala, Sweden).

\section{Immunochemical characterization of the large aggregating proteo-} glycan

For immunoblots, aggrecan was treated either with chondroitin sulphate lyases $A C / A B C$, with keratan sulphate hydrolyases or with a combination of these enzymes, then submitted to SDS-PAGE on preformed 4-15\% gradient gels (Pharmacia Phast system, Pharmacia/LKB). Subsequently they were blotted to polyvinylidenefluoride-membranes (Fluorotrans, Pall) by diffusion (16). The membrane was blocked by blotto $(20 \mathrm{~g} / \mathrm{l}$ dry milk powder in tris buffered salinc, $1 \mathrm{~h}$, room temperature) before incubation with monoclonal antibody (diluted appropriately in blocking solution) for $4 \mathrm{~h}$. 
Bound antibodies were detected by a peroxidase-conjugated second antibody from goat and visualized by the use of $0.05 \mathrm{~mol} / 1 \mathrm{Tris}-$ $\mathrm{HCl}$, pl 7.4 , containing $1.26 \mathrm{mmol} / 13,3^{\prime}$-diaminobenzidine tetrahydrochloride and $50 \mathrm{mg} / \mathrm{l} \mathrm{H}_{2} \mathrm{O}_{2}$.

\section{Antigen-inhibition-enzyme-immunoassay}

Antibodies, specific for keratan sulphate (4B3/D10) or the aggrecan-core-protein (4G4/A10) were sclected for the development of sensitive antigen-inhibition ELISAs. For determination of keratan sulphate the keratan sulphate-rich region of the large aggregating protcoglycan (aggrecan) was prepared. Briefly, aggrecan was digested with chondroitinase $A C / A B C$, purificd by gel-permeationchromatography and subsequently digested with trypsin. The keratan sulphate-rich region was isolated and purified by ion-cxchange chromatography. For determination of standard inhibition curves, variable amounts of the unlabelled and a constant amount of the biotin-labelled keratan sulphate-rich region were used. For determination of the aggrecan-core-protein content, the purified aggrecan was used as a standard. Microtitre-plates (96-well, high proteinbinding capacity, Greiner, Nürtingen, Germany) were coated overnight with $100 \mu \mathrm{l}$ per well of a rabbit-anti-mouse antiserum (DAKO, Kopenhagen, Denmark) diluted $1: 1000$ in $0.05 \mathrm{~mol} / \mathrm{l}$ $\mathrm{Na}_{2} \mathrm{CO}_{3} / \mathrm{NaHCO}_{3}$ buffer ( $\mathrm{pH} 9.6$ ), containing $200 \mathrm{mg} / 1 \mathrm{NaN}$. Thereafter, diluted antiserum was removed, and non-specific binding sites were blocked by a solution of $20 \mathrm{~g} / \mathrm{l}$ bovinc serum albumin (Behring, Marburg, Germany) in phosphate buffered saline $(200 \mu \mathrm{l}$ per well, $90 \mathrm{~min})$. All incubations were carried out at $37^{\circ} \mathrm{C}$ in a humidified atmosphere. Specific antibodies ( $100 \mu \mathrm{l}$ per well), diluted appropriately in blocking solution, were allowed to bind for $90 \mathrm{~min}$. To remove unbound antibody, wells were washed three times $\left(200 \mu \mathrm{l}\right.$ per well of $0.1 \mathrm{~mol} / 1 \mathrm{KH}_{2} \mathrm{PO}_{4} / \mathrm{K}_{2} \mathrm{HPO}_{4}$ buffer, $\mathrm{pH}$ 6.5). A solution $(100 \mu \mathrm{l})$ containing a mixture of biotin-labelled and unlabelled antigen (see below) was then added. To remove unbound antigen, wells were washed three times with $200 \mu \mathrm{l}$ of $0.1 \mathrm{~mol} / \mathrm{KH}_{2} \mathrm{PO}_{4} / \mathrm{K}_{2} \mathrm{HPO}_{4}$ ( $\mathrm{pH}$ 6.5). Thereafter peroxidase-conjugated streptavidin (Dianova, Hamburg, Germany), diluted in 0.2 $\mathrm{mol} / 1 \mathrm{KH}_{2} \mathrm{PO}_{4} / \mathrm{K}_{2} \mathrm{HPO}_{4}$ buffer ( $\mathrm{pH} 6.5$ ), containing fetal calf serum (volume fraction 0.2 ) was added (100 $\mu$ ll per well, $45 \mathrm{~min}$ ). Unbound streptavidin was removed by washing the plate 5 times ( 200 $\mu \mathrm{l}$ per well) with $0.1 \mathrm{~mol} / \mathrm{l}$ sodium citrate/citric acid ( $\mathrm{pH} 5.0$ ). Substrate solution $(100 \mu \mathrm{l})$ was added to the wells $(8 \mathrm{mg} 0$-phenylenediamine dissolved in $12 \mathrm{ml} 0.1 \mathrm{~mol} / 1$ citrate/citric acid pH 5.0 and $5 \mu \mathrm{H}_{2} \mathrm{O}_{2}(300 \mathrm{~g} / \mathrm{kg})$. Colour development was stopped by addition of $0.5 \mathrm{~mol} / 1 \mathrm{H}_{2} \mathrm{SO}_{4}(100 \mu \mathrm{l}$ per well). The plates were read using an ELISA plate reader (SLT, Overrath, Germany) at a wavelength of $492 \mathrm{~nm}$; absorbance at $690 \mathrm{~nm}$ was used for back-ground subtraction.

\section{Antigen}

To measure either the keratan sulphate content or the amount of aggrecan-core-protein present in the sample, standard-inhibition curves (constant amount of biotin-labelled antigen and increasing amounts of unlabelled antigen) were also determined on each plate. For measurement of keratan sulphate in the presence of serum, samples were diluted in a buffer consisting of $20 \mathrm{mmol} / 1 \mathrm{NaH}_{2} \mathrm{PO}_{4}$; $50 \mathrm{mmol} / 1 \mathrm{Na} 2 \mathrm{EDTA}(\mathrm{pH} 4.5$ ) with $10 \mathrm{~g} / \mathrm{l}$ bovine serum albumin and $100 \mu \mathrm{i} / 1$ Tween-20 prior to adding the biotin-labelled antigen (2). For determination of core-protein levels in the presence of serum, the samples were diluted in $10 \mathrm{~g} / 1$ bovine serum albumin in phosphate buffered saline, containing $1 \mathrm{~m} / / 1$ Tween-20 prior to adding the biotin-labelled antigen. Usually, sera were diluted $1: 5$, $1: 10$ and $1: 20$ in the appropriate buffer. In both cases, sera, which had been depleted of either keratan sulphate or aggrecancore-protein, were used for determination of standard-inhibition curves (see below). The keratan sulphate content of standard and sample is expressed as the glucosamine-content (nmol/l), and the amount of aggrecan-core-protein is expressed as the glycine-content $(\mathrm{nmol} / \mathrm{l})$.
Removal of keratan sulphate and aggrecan core-protein from serum

Sera used for determination of the standard inhibition curves were submitted to immunosorption by either the keratan sulphatespecific or the aggrecan-core-protcin specific antibody. Briefly, a polystyrene tube was coated overnight with a rabbit-anti-mouscimmunoglobulin antiscrum (DAKO, Kopenhagen, Denmark) diluted 1: 1000 in $0.05 \mathrm{~mol} / \mathrm{l} \mathrm{Na} \mathrm{CO}_{3} / \mathrm{Nal}^{-} \mathrm{CO}_{3}$ buffer (pH 9.6) containing $200 \mathrm{mg} / 1 \mathrm{NaN}_{3}$. Thereafter, antiserum was removed, and non-specific binding sites were blocked $(2 \mathrm{~h}, 20 \mathrm{~g} / \mathrm{l}$ bovine scrum albumin in phosphate buffered saline) prior to adding the specific antibody diluted appropriately in the blocking solution $(2 \mathrm{~h})$. Unbound antibody was removed by washing the tube three times with $0.1 \mathrm{~mol} / 1 \mathrm{KH} \mathrm{KHO}_{4} / \mathrm{K}_{2} \mathrm{HPO}_{4}(\mathrm{pH} 6.5$ ) before addition of the serum to be depleted of keratan sulphate and EDTA (final concentration $50 \mathrm{mmol} / \mathrm{l}$ ). Keratan sulphate or aggrecan-core-protein were allowed to bind to the antibody for $8 \mathrm{~h}$ or overnight. Depletion of the antibody-treated serum was checked by slot blot enzymc immuno assay. Depleted sera were aliquoted and stored at $-20^{\circ} \mathrm{C}$.

\section{Results and Discussion}

\section{Isolation and biochemical characterization of aggrecan}

Aggrecan was isolated from human articular cartilage and purified by several chromatographic steps (fig. 1). Fractions eluting between $0.9 \mathrm{~mol} / 1 \mathrm{NaCl}$ and $1.9 \mathrm{~mol} / 1$ $\mathrm{NaCl}$ from the Sepharose $\mathrm{Q}$ column were pooled and submitted to hydroxyapatite chromatography. The sample eluting between $0.13 \mathrm{~mol} / 1$ and $0.17 \mathrm{~mol} / \mathrm{l}$ $\mathrm{NaH}_{2} \mathrm{PO}_{4}$ from the hydroxyapatite column was submitted to size-exclusion chromatography on TSK 4000 . It revealed a single sharp peak in the void volume of the

Human articular cartilage

Extraction with $4 \mathrm{~mol} / \mathrm{l}$ guanidine- $\mathrm{HCl}$ in the presence of protease inhibitors

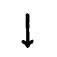

Buffer exchange to $7 \mathrm{~mol} / \mathrm{l}$ urea Chromatography on Sephadex G-25

\section{$\downarrow$}

Anion-exchange-chromatography on Sepharose Q FF linear $\mathrm{NaCl}$-gradient $(0.05-4 \mathrm{~mol} / \mathrm{l} \mathrm{NaCl})$

$$
\downarrow
$$

Aggrecan containing fractions eluted between 0.9 and $1.9 \mathrm{~mol} / \mathrm{l} \mathrm{NaCl}$

$\downarrow$

Hydroxyapatite chromatography

linear gradient $0.005-0.7 \mathrm{~mol} / \mathrm{l} \mathrm{NaH} \mathrm{PO}_{4}$

\section{$\downarrow$}

Large aggregating proteoglycan $0.13-0.17 \mathrm{~mol} / 1 \mathrm{NaH}_{2} \mathrm{PO}_{4}$

Fig. 1 Isolation and purification of the large aggregating proteoglycan (aggrecan) from human articular cartilage. 


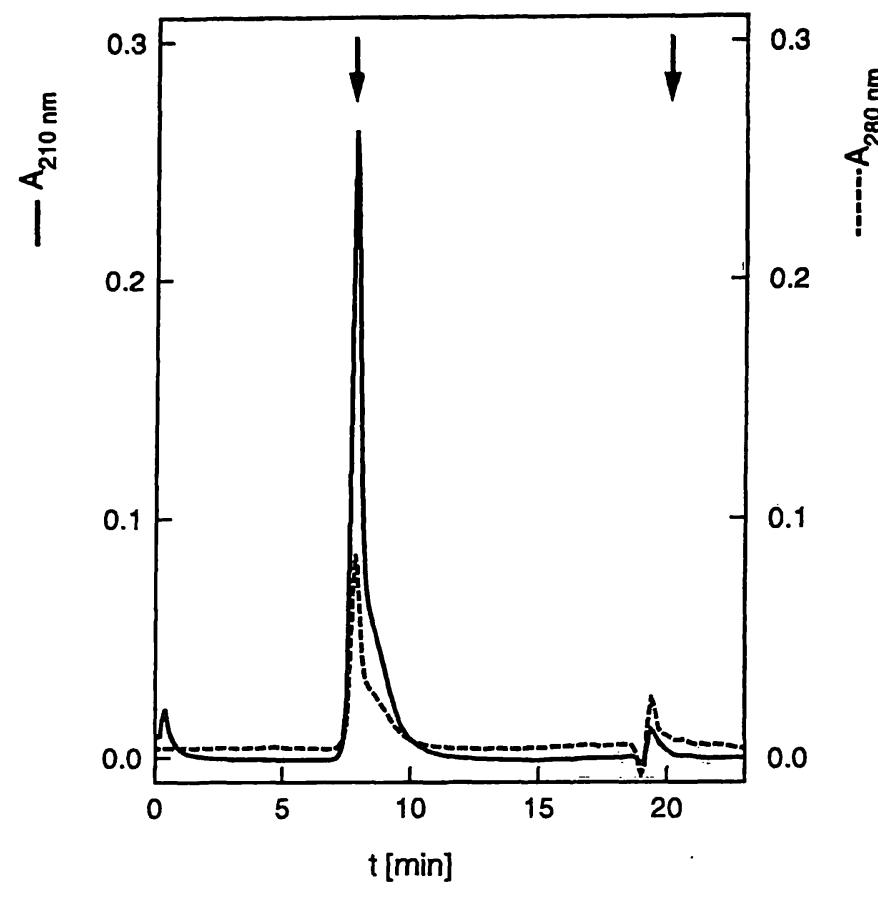

Fig. 2 Gel-permeation chromatography of aggrecan on TSK G $4000 \mathrm{SW}$. Purified aggrecan was submitted to analytical size exclusion chromatography on a TSK G $4000 \mathrm{SW}$ column $(7.5 \mathrm{~mm}$ $\times 300 \mathrm{~mm}$; precolumn TSK G SWP $7.5 \mathrm{~mm} \times 75 \mathrm{~mm}$ ), equilibrated with a $0.02 \mathrm{~mol} / /$ sodium phosphate buffer $(\mathrm{pH} \mathrm{6.0)}$ containing $0.3 \mathrm{~mol} / 1 \mathrm{NaCl}$ and $100 \mathrm{mg} / \mathrm{l}$ CHAPS. The sample was applied to the column and eluted at a flow rate of $0.8 \mathrm{ml} / \mathrm{min}$. Absorbance was monitored at $210 \mathrm{~nm}(-)$ and $280 \mathrm{~nm}(--), V_{o}$ and $V_{t}$ are indicated by arrows.

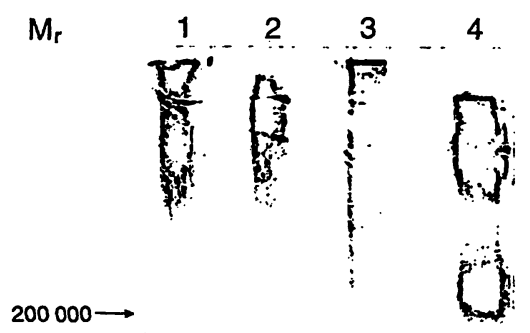

$96000 \longrightarrow$

$69000 \longrightarrow$

$45000 \longrightarrow$

$30000 \rightarrow$

Fig. 3 Diffusion blot of native and enzymatically digested biotinylated large aggregating proteoglycan. Biotinylated large aggregating proteoglycan from human articular cartilage was submitted to SDS-PAGE on a 4-15\% gradient gel and blotted onto nitrocellulose membrane.

1. native biotinylated sample; 2. sample after chondroitinase $\mathrm{ACl}$. $A B C$ treatment; 3. sample after keratanase treatment; 4. sample after treatment with condroitinase $\mathrm{AC} / \mathrm{ABC}$ and keratanase. column (fig. 2), indicating homogeneity of the isolated aggrecan. The identity of aggrecan was shown by enzymatic digestion with chondroitin sulphate lyases $\mathrm{AC} /$ $\mathrm{ABC}$ and keratan sulphate hydrolyases. The core-protein of aggrecan was labelled with biotin prior to digestion of the glycosaminoglycan chains; ,Digested and undigested samples were submitted to SDS-PAGE (4-15\% gradient) and diffusion blot onto nylon membrane. Biotinlabelled compounds were detected with avidin-peroxidase with diaminobenzidine as substrate. After digestion of aggrecan with a combination of the chondroitin sulphate lyases $\mathrm{AC} / \mathrm{ABC}$ and keratanases, a band corresponding to $M_{\mathrm{r}}$ of about 200000 , i. e. the size of aggrecan-core-protein was detected (fig. 3); the band above $M_{\mathrm{r}} 200000$ is most likely due to incomplete removal of the glycosaminoglycan-side chains. The same holds true for the additional band seen in figure 4c. No other bands, indicating the presence of smaller proteoglycans, could be detected. The amino acid and hexọsamine composition of aggrecan is given in table 1.

\section{Preparation and characterization of monoclonal antibodies}

The aggrecan preparation was used for immunization of mice. A series of more than 20 monoclonal antibodies was obtained. Two of these monoclonal antibodies were selected for further characterization and subsequently used for the development of enzyme-immunoassays. To

Tab. 1 Amino acid- and hexosamine-content of the purified large aggregating proteoglycan from human articular cartilage.

Amino acid contents are expressed in mol/1000 mol; the molar ratios of GalN/GlcN as well as (cGlcN/mol $+\mathrm{cGalN} / \mathrm{mol}) / \mathrm{amino}$ $\mathrm{acid} / \mathrm{mol}$ are given.

\begin{tabular}{lc}
\hline Amino acid & $\begin{array}{c}\text { Relative content } \\
(\mathrm{mol} / 1000 \mathrm{~mol})\end{array}$ \\
\hline Asp & 72 \\
Thr & 77 \\
Ser & 102 \\
Glu & 145 \\
Pro & 107 \\
Gly & 116 \\
Ala & 85 \\
Val & 59 \\
Met & 4 \\
Ile & 28 \\
Leu & 75 \\
Tyr & 29 \\
Phe & 34 \\
His & 16 \\
Lys & 14 \\
Arg & 37 \\
HexN/Protein & 0.91 \\
GlcN/Protein & 0.29 \\
GälN/Protein & 0.62 \\
GalN/GlcN & 2.14 \\
GlcN/GalN & 0.47 \\
\hline
\end{tabular}




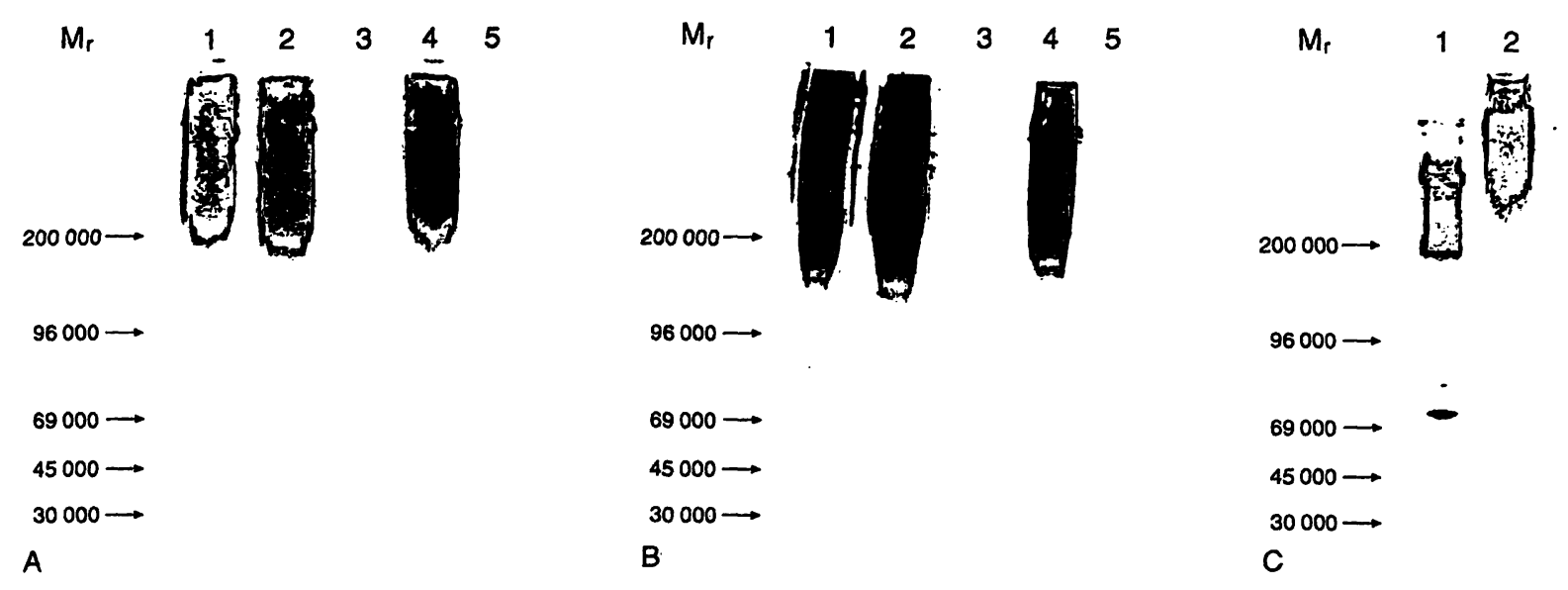

Fig. 4 Immunochemical characterization of the large aggregating proteoglycan from human articular cartilage. Diffusion blot of native large aggregating proteoglycan from human articular cartilage (Panel $A$ and $B$, lane 1 and 4 ), and the same material after digestion with chondroitinase $A C / A B C$ (Panel $A$ and $B$, lane 2), keratanase (Panel $A$ and $B$, lane 3), or chondroitinase $A C / A B C$ and keratanase (Panel $A$ and $B$, lane 5). Proteoglycans were submitted to SDS-PAGE on a 4-15\% gradient gel and subsequently blotted onto polyvinylidene-fluoride-membrane. Immunochemical

detection was performed with either the keratan sulphate-specific monoclonal antibody 4B3/D10 (Panel A) or 5D4 (Panel B). For immunochemical detection of the core-protein, aggrecan, digested with chondroitinase $\mathrm{AC} / \mathrm{ABC}$ and keratanase (Panel $\mathrm{C}$, lane 1), as well as native aggrecan (Panel $C$, lane 2) was submitted to SDSPAGE on a $4-15 \%$ gradient gel and subsequently blotted onto polyvinylidene-fluoride-membrane. Immunochemical detection was performed with the core-protein-specific monoclonal antibody 4G4/A10.

determine the specificity of these antibodies, native and enzymatic or chemically deglycosylated aggrecan was submitted to SDS-PAGE and Western-blot. The epitope, recognized by the monoclonal antibody $\mathrm{mAb} 4 \mathrm{~B} 3 / \mathrm{D} 10$ is completely removed by keratanase digestion (fig. $4 \mathrm{a}$ ), indicating that this antibody reacts with keratan sulphate chains present on aggrecan. In this respect the antibody seems to be similar to the previously described keratan sulphate-specific monoclonal antibody mAb 5D4 (fig. 4b) (1). This monoclonal antibody, and several others with the same specificity, which have been described in the meantime $(2,21)$, were shown to recognize a highly sulphated epitope present at the non-reducing end of keratan sulphate chains $(8,21=23)$. Since this epitope is a common feature of keratan sulphate chains, these antibodies react equally well with keratan sulphate isolated from different tissues and species $(9-11,24,25)$. In contrast, the monoclonal antibody mAb 4B3/D10 shows high specificity for the keratan sulphate chains present on aggrecan from human articular cartilage, but little or no reactivity with keratan sulphate isolated from human intervertebral disc (manuscript in preparation). These findings indicate that the monoclonal antibody $\mathrm{mAb} 4 \mathrm{~B} 3 / \mathrm{D} 10$ recognizes a novel epitope on the keratan sulphate chain, which is preferentially expressed on the large aggregating proteoglyçan in cartilage. In contrast, reactivity of aggrecan with the monoclonal antibody mAb 4G4/A10 is neither influenced by enzymatic nor by chemical deglycosylation of aggrecan (fig. 4c), indicating that this antibody recognizes an epitope present on the core-protein of aggrecan.

Development of enzyme immunoassays specific for keratan sulphate- and coreprotein-epitopes of the large aggregating proteoglycan from human articular cartilage

In the course of chronic inflammatory and degenerative joint diseases cartilage is degraded by the action of proteases and oxygen radicals. Therefore, proteoglycan fragments, released from the cartilage into the peripheral blood, may be useful markers of cartilage degradation.

So far, only monoclonal antibodies with a specificity similar to the monoclonal antibody mAb 5D4 have been used for the measurement of keratan sulphate in serum of patients with different joint diseases (3-7). However, using these antibodies, only a poor correlation between disease activity, cartilage destruction and the keratan sulphate levels in the serum was obtained. In contrast to these results, analysis of keratan sulphate levels in synovial fluid gave rather promising results. This might be explained by the lack of cartilage specificity of the antibodies used. Even though little is known about the metabolism of keratan sulphate, it is clear that keratan sulphate is released into the serum not only from cartilage, but also from intervertebral disc, the blood vessels and perhaps other organs $(6,9-11,24-25)$. Therefore, when using antibodies which do not discriminate between keratan sulphate from these different sources, analysis of keratan sulphate levels in serum might be influenced strongly by keratan sulphate from other sources than cartilage. In contrast, analysis of keratan sulphate in synovial fluid, which is released mainly from 
cartilage, is affected only slightly by keratan sulphate from other origins.

Therefore, the use of monoclonal antibodies with high specificity for epitopes expressed exclusively or at least preferentially on keratan sulphate chains of the large aggregating proteoglycan from articular cartilage seems to be necessary for a specific measurement of keratan sulphate release from cartilage into the serum. Moreover, the determination of a pattern of cartilage-specific proteoglycan-epitopes, present in the serum, might give a better correlation between cartilage destruction and disease activity than the determination based on only one epitope. We therefore made novel monoclonal antibodies with higher specificity for cartilage-specific epitopes of the large aggregating proteoglycan.

As little is known about the size and the composition of proteoglycan fragments released from cartilage $(26,27)$ we decided to use these antibodies for the development of a sensitive antigen-inhibition-assay. This type of assay does not depend on repetitive epitopes, or on the expression of two defined different epitopes on one fragment, a prerequisite for classical sandwich immuno assays. In this type of antigen-inhibition assay a constant amount of biotin-labelled antigen is added to the sample, and competes with the unlabelled antigen present in the sample for binding to the immobilized antibody. Biotinlabelled antigen, bound to the antibody, is detected by the use of streptavidin-peroxidase and o-phenylene diamine as substrate. An example of the standard-inhibition curves for both assays described is shown in figure 5 .

One major point, which has not been adressed properly in previous work, is the interaction of keratan sulphate with serum components. In fact, strong interactions between serum and keratan sulphate have been observed. This has been successfully overcome by the use of either $50 \mathrm{mmol} / \mathrm{l}$ EDTA and $100 \mu \mathrm{l} / \mathrm{l}$ Tween-20 (4B3/D10) or $50 \mathrm{mmol} / \mathrm{l}$ EDTA and $1 \mathrm{ml} / \mathrm{l}$ Tween-20 (5D4) in the sample buffer. The observation that Tween-20 and EDTA are required for counteracting the interaction between keratan sulphate and serum points to a $\mathrm{Ca}^{2+}$-dependent interaction. In the case of the core-proteinspecific antibody, there is virtually no interaction between the matrix and the large proteoglycan added. The keratan sulphate content of the standard is expressed as the molar amount of glucosamine rather than as $\mathrm{g} / \mathrm{l}$ of keratan sulphate; the core-protein-content of the standard is expressed as the molar amount of glycine. In our opinion, expressing the keratan sulphate-content as glucosamine-content reflects more closely the real keratan sulphate-content, since the keratan sulphate-specific antibodies recognize epitopes containing at least one glucosamine-residue. Another important point when

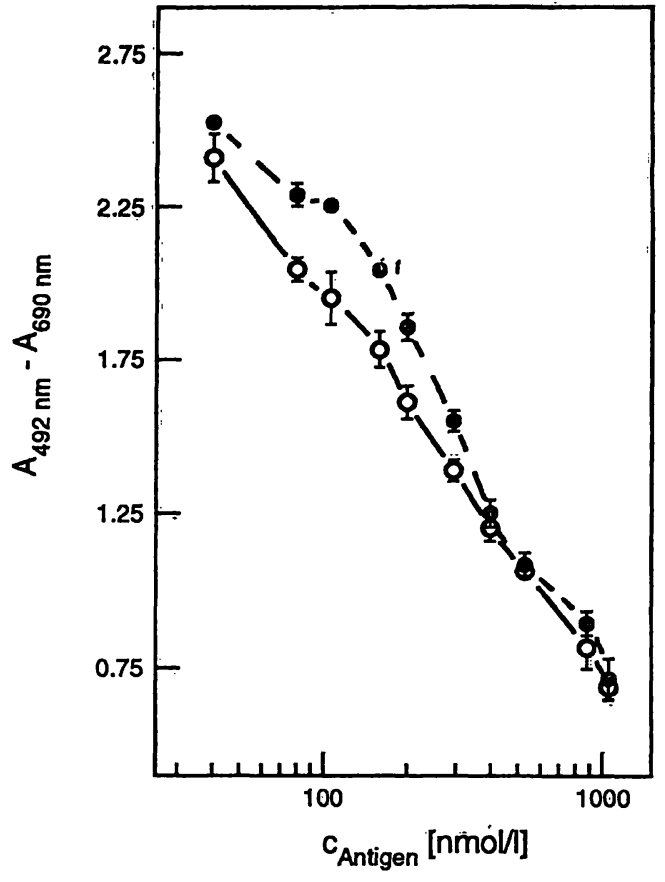

Fig. 5 Standard inhibition-curves obtained with the monoclonal antibody 4G4/A10. Increasing amounts of aggrecan (40 nmol/1 to $1060 \mathrm{nmol} / \mathrm{l}$, expressed as glycine content) were added to serum which had been depleted of core-protein. A constant amount of biotin-labelled aggrecan ( $112 \mathrm{nmol} / \mathrm{l}$, expressed as glycine-content) was added and the sera were allowed to bind to the immobilized antibodies. Bound, biotin-labelled antigen was detected with peroxidase-conjugated streptavidin as described under Material and Methods.

- 0 - Standard inhibition curve obtained in the presence of $20 \mathrm{~g} / 1$ bovine serum albumin

- O- Standard inhibition curve obtained in the presence of coreprotein-depleted serum

considering the specificity of the assay is the source of antigen used, because different binding affinities for antigens will greatly influence the outcome of the assay $(6,10)$. In our opinion it is absolutely necessary to use aggrecan from human articular cartilage as competing labelled antigen in this type of assay.

The reliability of these assays was analysed with respect to sensitivity and precision. For the within-run- and between-run imprecision coefficient of variation $(\mathrm{CV})$ values of $\leq 10 \%$ were obtained. The $C V$ values were determined for keratan sulphate concentrations of 1790 nmol/1 ( $1: 5$ diluted serum, $\mathrm{n}=10, \mathrm{CV}=7.7 \%)$ and core-protein concentrations of $66 \mathrm{nmol} / 1$ (1:5 diluted serum, $\mathrm{n}=10, \mathrm{CV}=9.9 \%)$. Under the conditions described the lower detection limit of the assays was about $10 \mathrm{nmol} / \mathrm{l}$ glycine (4G4/A10) and $20 \mathrm{nmol} / \mathrm{l}$ glucosamine (5D4, 4B3/D10) respectively.

The assays described in the present report allow the sensitive determination of cartilage-specific keratan sulphate and aggrecan core protein levels in human sera and will now be used for the study of different inflammatory and degenerative joint diseases. A major advantage of these novel assays lies in their higher cartilage 
specificity, which will allow the sensitive and specific detection of cartilage damage not only in synovial fluid samples (3) but also in serum samples, an essential prerequisite for a broad application of these assays. The assays will be useful in the analysis of cartilage metabolism and breakdown in joint diseases, in monitoring .disease progression, but also in the search for improved drugs. They might contribute also to an understanding

\section{References}

1. Caterson, B., Christner, J. E. \& Baker, J. R. (1983) Identification of a monoclonal antibody that specifically recognizes corneal and sceletal keratan sulphate. J. Biol. Chem. 258, 8848-8854

2. Thonar, E., Lenz, M. E., Klintworth, G. K., Caterson, B., Pachman, L. M., Glickman, P., Katz, R., Huff, J. \& Kuettner, K. E. (1985) Quantification of keratan sulphate in blood as a marker of cartilage catabolism. Arthritis Rheum. 28, 1367-1376.

3. Saxne, T., Heinegard, D. \& Wollheim, F. A. (1987) Cartilage proteoglycans in synovial fluid and serum in patients with inflammatory joint disease. Arthritis Rheum. 30, 972-979.

4. Thonar, E. J. M. A., Manicourt, D. M., Williams, J., Lenz, M. E., Sweet, M. B. E., Schnitzer, T. J., Otten, L., Glant, T. \& Kuettner, K. E. (1991) Circulating keratan sulphate: A marker of cartilage proteoglycan catabolism in osteoarthritis. J. Rheumatol. (suppl. 27) 18, 24-26.

5. Seibel, M. J., Towbin, H., Braun, D. G., Kiefer, B., Müller, W. \& Paulsson, M. (1989) Serum keratan sulphate in rheumatoid arthritis and different clinical subsets of osteoarthritis. In: Keratan Sulphate (Greiling, H. \& Scott, J. E., eds.) The Biochemical Society, London: pp. 191-198.

6. Greiling, H. \& Scott, J. E. (1989) Keratan Sulphate, The biochemical Society, London.

7. Spector, T. D., Woodwead, L., Hall, G. M., Hammond, A., Williams, A., Butler, M. G., James, L. T., Hart, D. J., Thompson, P. W. \& Scott, D. L. (1992) Keratan sulphate in rheumatoid arthritis, osteoarthritis, and inflammatory diseases. Ann. Rheum. Dis. 51, 1134-1137.

8. Mehmet, H., Scudder, P., Tang, P. W., Hounsell, E. F., Caterson, B. \& Feizi, T. (1986) The antigenic determinants recognized by three monoclonal antibodies to keratan sulphate involve sulphated hepta- or larger oligosaccarides of the poly(N-acetyl-lactosamine) series. Eur. J. Biochem. 157, 385-391.

9. Funderburgh, J. L., Caterson, B. \& Conrad, G. W. (1987) Distribution of proteoglycans antigenically related to corneal keratan sulphate proteoglycan. J. Biol. Chem. 262, 11 634-11640.

10. Feizi, T. (1989) Keratan sulphate oligosaccharides, members of a family of antigens of the poly- $\mathrm{N}$-acetyllactosamine series. In: Keratan Sulphate (Greiling, H. \& Scott, J. E., eds.) The Biochemical Society, London: pp. 21-29.

11. Baker, J. R. (1989) Studies of keratan sulphates of aorta and cartilage utilizing MAb 6D2. In: Keratan Sulphate (Greiling, H. \& Scott, J. E., eds.) The Biochemical Society, London: pp. 30-38.

12. Hascall, V. C. \& Kimura, J. H. (1982) Proteoglycans: Isolation and characterization. Methods Enzymol. 82, 769-800.

13. Heinegard, D. \& Sommarin, Y. (1987) Isolation and characterization of proteoglycans. Methods Enzymol. 144, 319-372.

14. Stöcker, G. \& Fischer, D.-C. (1990) Isolation and characterization of proteoglycans from different tissues. J. Chromat. 521, $311-324$

15. Stöcker, G., H. E. Meyer, C. Wagener \& Greiling, H. (1991) Purification and $\mathrm{N}$-terminal amino acid sequence of a chondroitin sulphate/dermatan sulphate proteoglycan isolated from in- of the relation of inflammation and destruction in joint diseases.

\section{Acknowledgement}

We wish to thank $E$. von Heel for excellent technical assistance. This work was supported by grant No. 01 VM $8915 / 6$ by the Bundesministerium für Forschung und Technik, Bonn, Germany. tima/media preparations of human aorta. Biochem. J. 274 415-420.

16. Stöcker, G., Lückge, J., Greiling, H. \& Wagener, C. (1989) Characterization of biotin-labeled proteoglycans by electrophoretic separation on minigels and blotting onto nylon membranes prior and after enzymatic digestion. Anal. Biochem. 179, 245-250.

17. Oike, Y., K. Kimata. T. Shinomura, K. Nakazawa \& Suzuki, S. (1980) Proteinase activity in chondroitin lyase and endo$\beta$-D-galactosidase preparations and a method to abolish their proteolytic effect on proteoglycan. Biochem. J. 191, 193-207.

18. Edge, A. S. B., Galtynek, C. P., Hof, L., Reichert, Jr., L. E. \& Weber, P. (1981) Deglycosylation of glycoproteins by trifluormethanesulfonic acid. Anal. Biochem. 118, 131-137.

19. Soroka, C. J. \& Farquhar, M. G. (1991) Characterization of a novel heparan sulphate proteoglycan found in extracellular matrix of liver sinusoids and basement membranes. J. Cell. Biol. 113, 1231-1241.

20. Köhler, G. \& Milstein, C. (1975) Continuous culture of fused cells secreting antibodies of predefined specificity. Nature 256 , 495-497.

21. Zanetti, M., Ratcliffe, A. \& Watt, F. M. (1985) Two subpopulations of differentiated chondrocytes identified with a monoclonal antibody to keratan sulphate. J. Cell Biol. 101, 53-59.

22. Scudder, P., Tang, P. W., Hounsell, E. F., Lawson, A. M., Mehmet, H. \& Feizi, T. (1986) Isolation and characterization of sulphated oligosaccharides released from bovine corneal keratan sulphate by the action of endo- $\beta$-galactosidase. Eur. J. Biochem. 157, 365-373.

23. Hounsell, E. F., Feeney, J., Scudder, P., Tang, P. W. \& Feizi, T. (1986) ${ }^{1} \mathrm{H}-\mathrm{NMR}$ studies at $500 \mathrm{MHz}$ of a neutral disaccharide and sulphated di-, tetra-, hexa- and larger oligosaccharides obtained by endo- $\beta$-galactosidase treatment of keratan sulphate. Eur. J. Biochem. 157, 375-384.

24. Greiling, H., Löffler, H. J. \& Stuhlsatz, H. W. (1989) Distribution of keratan sulphate-containing proteoglycans in human aorta and their possible role in the calcification of aorta. In: Keratan Sulphate (Greiling, H. \& Scott, J. E., eds.) The Biochemical Society, London: pp. 226-238.

25. Wight, T. N., M. W. Lark \& M. G. Kinsella (1987) Blood vessel proteoglycans. In: Biology of Proteoglycans (Wight, T. N. \& Mecham, R. P., eds.) Acta Press, pp. 267-295.

26. Liszt, F., Schnittker-Schulze, K., Stuhlsatz, H. \& Greiling, H. (1991) Composition of proteoglycan fragments from hyaline cartilage produced by granulocytes in a model of frustrated phagocytosis. Eur. J. Clin. Chem. Clin. Biochem. 29, 123130.

27. Sandy, J., Flannery, C. R., Neame, P. J. \& Lohmander, L. S. (1992) The structure of aggrecan fragments in human synovial fluid. J. Clin. Invest. 89, 1512-1516.

PD. Dr. H.-D. Haubeck

Institut fur Klinische Chemie und Pathobiochemie Pauwellstraße 30

D-52074 Aachen

Germany 
